\title{
Impact of the Guaranteed Health Plan with a single community premium on the demand for private health insurance in Chile
}

\author{
Eduardo Bitran, Fabián Duarte, Dalila Fernandes \\ and Marcelo Villena
}

\begin{abstract}
In 2012, a Guaranteed Health Plan for the private health system was submitted to the Chilean National Congress, with the aim of offering a standardized flat-rate health-care plan. This paper evaluates the impact that the introduction of this plan would have on the demand for health insurance. The results suggest that the private insurance portfolio would shrink by $12.39 \%$, which means that around 400,000 people would switch to the public system, thereby exacerbating the adverse-selection problem faced by the system and imposing an additional fiscal burden of US\$200 million per year.
\end{abstract}

\section{Keywords}

Health, private sector, health insurance, prices, supply and demand, health services, public sector, statistical data, Chile

JEL classification

1130, C250

\section{Authors}

Eduardo Bitran is Executive Vice President of the Production Development Corporation (CORFO). Email: eduardo.bitran@uai.cl.

Fabián Duarte is Assistant Professor at the Economics Department of the Faculty of Economics and Business of the University of Chile. Email: fabduarte@fen.uchile.cl.

Dalila Fernandes is Accounts Director at App Annie. Email: dalilafernandes@gmail.com. Marcelo Villena is Vice-Dean of the Faculty of Engineering and Sciences at Adolfo Ibáñez University (UAI), Chile. Email: marcelo.villena@uai.cl. 


\section{Introduction}

The Chilean experience in the provision of health insurance is quite unusual. Firstly, few countries offer the option of choosing between multiple health insurance plans, as is the case in Chile. Secondly, the Chilean system displays a structural segmentation, with a low-income and high-risk population covered by public insurance through the National Health Fund (FONASA), and a high-income, low-risk population. The latter usually contracts insurance with private health insurance institutions (Isapres), thereby raising a serious problem of adverse selection. In 2004, a general regime of explicit health guarantees (GES) was introduced, which was pioneering in Latin America in seeking to establish care rights for patients and thus foster greater systemic equity (see Missoni and Solimano, 2010). Despite these reforms, the system continued to show evidence of adverse selection on the demand side.

In this context, the Health Reform Commission (CRS), set up by the Government in 2011, proposed a new Guaranteed Health Plan (PGS), designed to offer all users of the private system a flat-rate plan with standardized characteristics. This was submitted to the National Congress in 2012. Under this new plan, the premium is independent of age and gender and is charged on each member of the family group (in other words the contributor and dependants) and is financed by a $7 \%$ mandatory payroll deduction from the individual. If surpluses are generated from the mandatory contribution, the affiliate may use the difference to purchase supplementary insurance in the Isapre to which he/she contributes, subject to a table of risk factors. Should the mandatory contribution be insufficient, the affiliate must provide an additional contribution to make up the difference. ${ }^{1}$

According to CRS estimates, a PGS value of up to 21,000 Chilean pesos (Ch\$21,000) is foreseen for 2011, assuming 50\% coverage of the FONASA level-1 free choice modality (MLE) rate. ${ }^{2}$ However, bargaining in the Senate has significantly reduced the co-payments, which is likely to push up the price of PGS.

The Guaranteed Health Plan combines the benefits already defined in GES, with additional coverage for catastrophic illnesses (CAEC). It also covers a group of diseases excluded from the GES plan, for which a network of providers will be specified; and it provides for a level of benefits that at least match the specifications of the Free Choice Modality of level 1 of the FONASA public insurance regime. In addition, the Guaranteed Health Plan will eliminate the waiting period and pre-existing conditions for private-system affiliates who wish to contract health insurance within the Isapre system. This measure allows individuals already affiliated to the private system to move between different insurers without restriction. This would clearly help mitigate the problem of affiliates who become captives of an Isapre when they reach a certain age or develop a chronic disease. By eliminating the waiting period and pre-existing conditions within the private system, and including a risk compensation fund that makes it possible to compensate Isapre plans that have a larger proportion of higher-risk affiliates, PGS tries to increase competition within the system and bring down entry barriers for new Isapres.

Nonetheless, the plan has fuelled debate around the consistency of its benefits. On the one hand, the introduction of a flat rate will mean a higher premium for certain groups of affiliates, who will be unable to finance the plan from their mandatory contribution alone. Using data from 2010, the authors estimate that at least $13 \%$ of affiliates, or close to 190,000 contributors, pay a premium that

\footnotetext{
1 In this case, the option of contracting supplementary insurance is also left free.

2 See "Informe Comisión - Octubre 2011. Evaluar la factibilidad de crear un Plan Garantizado de Salud (PGS) al interior del sub-sistema de ISAPRE" [online] https://www.politopedia.cl/wp-content/uploads/2016/06/Informe-Comisi\%C3\%B3nPGS.2011.pdf.
} 
is less than the PGS rate. ${ }^{3}$ Moreover, PGS does not eliminate the waiting periods and pre-existing conditions for users wishing to move from the public system to an Isapre. The demand for public or private health insurance may therefore change according to the effects of the new policy on different social groups. Some groups will be more attracted to the Isapre system after the reform, while others will decide to move to FONASA. Young people facing increased premiums but with low health risks, and therefore low health costs, might naturally decide to move to FONASA. ${ }^{4}$ Large families facing a high family premium, due to the per capita payment of the PGS rate, would also be encouraged to leave the private health system. ${ }^{5}$ Thus, one of the key issues is how the reform will impact on demand between the two systems: Isapres and FONASA. This is the main focus of the present research. Although there are also considerations and pressures on the supply side, these are beyond the scope of this study.

The effect of the introduction of PGS on the Isapre system and FONASA is evaluated by developing a model to determine the demand for Isapres and FONASA for each affiliate, considering sociodemographic characteristics, the characteristics of the supply of services and user preferences. ${ }^{6}$ The following variables should be taken into account: income level, risk, size of the family nucleus, age, gender and the conditions of the services offered by each system in each region of the country.

The model should therefore consider the specific features of the Chilean health system, such as the fact that dependent workers are required to purchase health insurance through a contribution consisting of a percentage of their wage; and the insurance alternatives include private plans offered by the Isapres and a single public system plan, FONASA, both of which have different pricing schemes.

This article is organized as follows. Section II discusses the relevant literature, both international and national, and section III describes the discrete-choice model, which makes several improvements on previous studies in Chile. Section IV describes the information used to calibrate the models and the descriptive statistics of the main variables used. Section $V$ reports the study's key results, in particular the impact on demand of the implementation of PSG; and the last section sets forth the main conclusions and policy recommendations.

\section{Literature review}

Since the seminal study by Akerlof (1970), great attention has been paid to the effect of information asymmetry on decision-making in the health-care market. On the one hand, health insurance markets are prone to adverse selection because insurees know much more about their own health risks than the insurers, which leads to very generous coverage attracting high-risk affiliates. On the other hand, information asymmetry in the doctor-patient relationship can contribute to the overuse of health services, as the risk coverage is greater, thereby generating moral hazard.

Studies of the influence of moral hazard on decisions about choosing health insurance are based on expected utility maximization theory. Friedman (1974), for example, suggests a discrete-choice model for choosing between health insurance alternatives, which makes it possible to make inferences about perceived risk aversion with respect to the alternatives. The study, conducted for exploratory purposes in

3 According to estimates made of the PGS price, a minimum income of about $\mathrm{Ch} \$ 320,000$ would be required for a single person to be insured through the mandatory contribution under PSG (Copetta, 2011). About 50,000 people would be unable to pay for PGS with the mandatory contribution; however, this estimate is biased because it does not consider the effect of dependants on the final price or on beneficiaries who pay more than the additional contribution ( $70 \%$ of the Isapre portfolio), many of whom would also suffer increases in the cost of their plans.

4 The authors estimate that about $22 \%$ of young people aged under 25 years pay a lower premium than they would pay in PGS, compared to just $11 \%$ of the rest of the population.

5 The authors estimate that about $25 \%$ of families with more than three members pay a lower premium than they would pay under PGS, compared to just $8 \%$ of families with fewer than three members.

6 The study does not model or estimate supply, given its great complexity; so the results are only partial equilibria. 
the United States, finds that family groups are less-risk averse than individuals. In subsequent research, Feldman proposes an analysis of the sensitivity of American workers' choices in relation to the health plan premiums paid directly by them (Feldman and others, 1989). The results show that individuals are highly sensitive to what they themselves pay directly. Cutler and Reber (1998) analyse the costs of adverse selection using information on how Harvard University employees choose their health plans. The authors consider a reform introduced by the institution, which in 1995 changed from a system of generous subsidies to one that only subsidizes a fixed amount of each insurance, independently of the plan and the premium. The results show that the reform reduced the costs borne by the University, since employees started to choose cheaper plans.

For the specific case of Chile, research in the field of health insurance only began in the 1990s, so it is sparse. Sapelli and Torche (1998) analyse factors underlying the choice of health insurance using the Survey of National Socioeconomic Characterization (CASEN) for 1990 and 1994. They conclude that the most important variables when deciding between public and private insurance are income, age and the individual's sector of residence. They also find that private information on the individual's health status generates adverse selection against private insurers, whereas public information on health status produces adverse selection against the public insurer. In later studies using CASEN for 1990 and 1996, Sapelli and Torche (2001) corroborate the importance of income and sector of residence in determining the individual's preference, but also add the relevance of the insurance price and expected out-of-pocket expenses in the form of co-payments. The authors stress that, at higher levels of expected health expense, public insurance becomes more attractive, so income cannot be the only variable explaining the choice of health insurance alternatives. Nonetheless, the study is limited by using a table of risk factors from a single private insurer. Although private insurers' risk factor tables are mutually correlated, price variations may reflect more than risk adjustment alone, since the different basic premiums charged in each plan depend on the type of coverage offered. The use of a single table thus fails to represent the average price of all insurers. To avoid this problem, the present study uses a vector of the average prices affiliates pay, according to age, gender, income level and number of family dependants, which has already incorporated the risk factors, the basic premium and individual preferences about whether or not to make an additional payment on top of the mandatory contribution.

Sapelli and Vial (2003) analyse adverse selection and expected expenditures in health systems. Their study confirms the problem of adverse selection in FONASA due to observable variables in the decision models; but the results do not identify adverse selection in Isapres, presumably owing to the design and variety of these plans, in which prices discriminate by risk.

Sanhueza and Ruiz-Tagle (2002) highlight the importance of the gender and age composition of the family nucleus. Yet one of the greatest shortcomings in this study is that the results of the health status variable show evidence of adverse selection against the private system, contrary to what might be expected in this system given the problem of pre-existing conditions. In another study, Tokman, Marshall and Espinosa (2007) find that the likelihood of a person being affiliated to an Isapre increases with income and decreases with the risk of members of the family group. They also find that the probability of affiliating to an Isapre increases with the availability of private beds in the region in which they live, among other factors.

Dawes Ibáñez (2010) analyses the effects of the implementation of the GES plan in the choice between public and private health systems, by comparing affiliates' preferences for the two health systems before and after implementation of the reform, using data from the 2000 and 2006 CASEN surveys. The authors use the Sapelli and Torche (2001) approach, drawing on the contributions made by Tokman, Marshall and Espinosa (2007). The results of the model before the reform concur with previous studies, highlighting the importance of income and risk in the choice of health system, and also adding the positive effects of having a spouse, education level and working in large firms on the probability of choosing private health insurance. In the post-reform analysis, the results suggest a weaker influence 
of individual health risk on the individual's preference, which the authors suggest is due to the better coverage of catastrophic risks in the GES plan, thereby creating a risk pool that reduces the difference in prices paid for private insurance. Nonetheless, a major shortcoming in the Dawes Ibáñez (2010) study is that it compares the pre- and post-reform situations with a six-year time interval, in which many other factors may have influenced changes in health-insurance preferences. ${ }^{7}$

Lastly, research by Duarte (2012) analyses the price elasticity of health expenditures, indicating possible preferences that could be invoked when analysing the choice of plans. Duarte uses data compiled from records of the Chilean private health insurance market and shows that high-income individuals are five times more price sensitive than low-income ones. The study does not cover the public system, however, since it works only with information from Isapre affiliates.

The aforementioned studies have focused on measuring the effect of prices and risk on individual choice in the Chilean case; but little has been done to analyse the influence of the quality of the systems and how this affects the choice of health insurance. The present study refines the analysis, by adding the quality component to improve the model's explanatory capacity. This should make it possible to identify individuals' preferences and their patterns of substitution between the different health systems more effectively, and thus predict the impact of PGS more accurately and obtain better results in the characterization of the groups affected by the reform.

\section{The model}

This study develops a discrete-choice decision model that simulates the demand for private health plans, but does not consider structural changes on the supply side. For a model to fit the discretechoice framework, the alternatives available to choose from must be mutually exclusive; the set of alternatives must contain all the options available to the individual making the decision; and there must be a finite number of options. The individual chooses, from all the available alternatives, the one that gives him/her the greatest utility.

The individual's utility function is modelled using the random-utility approach, the application of which to economics was initially proposed by McFadden and later developed by Manski. Under this approach, utility functions are treated as random, to reflect not a lack of rationality but rather the observer's lack of information on the characteristics of the alternatives or individuals. This model assumes that the utility of the individual $\left(U_{i}\right)$ can be separated additively into an observable deterministic component $\left(\varepsilon_{i}\right)$ and an unobservable random component $\left(V_{i}\right)$ for each alternative. Thus, considering individuals who choose different insurance systems:

$$
\begin{gathered}
U_{i I}=V_{i I}+\varepsilon_{i I} \\
U_{i F}=V_{i F}+\varepsilon_{i F}
\end{gathered}
$$

where $U_{i I}$ represents the utility that individual $i$ obtains from the Isapre health insurance (subindex I), and $U_{i F}$ is the utility individual $i$ obtains by choosing the FONASA insurance (subindex F). The component $\varepsilon_{i}$ captures all factors that affect utility but are not included in $V_{i}$. The probability that individual $i$ selects the private health system is therefore:

\footnotetext{
7 During these years, for example, inequality indicators in Chile fell sharply, which may influence the reduction in the income effect. Moreover, the number of Isapre plans shrank from 16,696 in December 2003 to 7,454 in January 2006, indicating lower price discrimination in private plans as a result of the restrictions implemented by the Isapres Law. Since price discrimination in this case involves the creation of more affordable plans for lower-income affiliates, this could be a relevant factor in making the private health system less attractive. Another limitation is that the implementation of GES cannot be analysed using control groups, since it applies to both Isapre and FONASA affiliates. Since GES is a new attribute of both the public and the private insurance, it cannot be claimed a preference for one or the other is a result of its implementation.
} 


$$
\begin{gathered}
P_{i f}=\operatorname{Prob}\left(U_{i I}>U_{i F}\right) \\
=\operatorname{Prob}\left(V_{i I}+\varepsilon_{i I}>V_{i F}+\varepsilon_{i F}\right) \\
=\operatorname{Prob}\left(\varepsilon_{i F}+\varepsilon_{i I}<V_{i I}+V_{i F}\right)
\end{gathered}
$$

This consists of the cumulative probability that each random term $\varepsilon_{i F_{-}} \varepsilon_{i I}$ is below the value observed for $V_{i I-} V_{i F}$. For example, for logit models, the error term is distributed according to the extreme value density function. So:

$$
P_{i I}=\int I\left(\varepsilon_{i F}-\varepsilon_{i I}<V_{i I}-V_{I F}\right) f\left(\varepsilon_{i}\right) d \varepsilon_{i}
$$

where $I(\cdot)$ is the indicator function, equal to 1 when the expression in parentheses is true and 0 otherwise. In this theoretical framework, we assume the following utility functions:

$$
\begin{gathered}
U_{i I}=\alpha\left(Y_{i}-P_{i I}\right)+\beta X_{i I}+\gamma X_{i I} Z_{i}+\delta Z_{i}+\varepsilon_{i I} \\
U_{i F}=\alpha\left(Y_{i}-P_{i F}\right)+\beta X_{i F}+\gamma X_{i F} Z_{i}+\delta Z_{i}+\varepsilon_{i F}
\end{gathered}
$$

where

$Y_{i}=$ the individual's income;

$P_{i I}=$ price of private insurance charged by the Isapre for the individual $i$;

$P_{i F}=$ price of FONASA public insurance for individual $i$, corresponding to $7 \%$ of individual income, or $0.07 Y_{i}$;

$X_{i I}=$ vector of attributes that Isapre health insurance offers the individual $i$;

$X_{i F}=$ vector of attributes that the FONASA health insurance offers to individual $i$;

$Z_{i}=$ vector of sociodemographic characteristics of individual $i$;

Equations (5) and (6) represent the utility function of Isapres and FONASA for individual $i$, respectively. Preferences are assumed stable over time.

The expected utility for each alternative is considered to depend positively on net income after the insurance premium has been paid. So, as health insurance becomes more expensive, its expected utility declines. Expected utility also depends on the attributes of the service delivered by the health plan: the higher the quality, the greater the expected utility. This is empirically supported by an opinion survey conducted by the Chilean Health Superintendency, which shows that the quality of medical care, the speed of care and the quality of the doctors are among the characteristics most highly valued by users of the private system. In the public system, however, one of the most prized characteristics is the low cost of care, in other words low co-payment levels (Superintendency of Health, 2012). The individual's sociodemographic characteristics also influence the level of utility perceived from a health insurance policy. Someone who is more risk averse, for example, tends to value greater coverage and be less sensitive to price; while an individual who resides in rural areas where there are few private hospitals tends to value public health insurance more highly.

When deciding on a health system, each individual evaluates the difference between the utility of being in the Isapre system and the utility of being in FONASA, and chooses the option that maximizes his/her utility. Thus, if the difference is positive, private insurance is chosen; if the difference is negative, public insurance is preferred. 
Subtracting equation (6) from (5), gives:

$$
U_{i I}-U_{i F}=\alpha\left(0.07 Y_{i}-P_{i I}\right)+\beta \Delta X_{i}+\gamma \Delta X_{i} Z_{i}+\Delta \varepsilon_{i}
$$

Unlike previous studies, the model being proposed here specifies that the vector of health insurance attributes consists of: (i) a vector of observable quality and service characteristics, $\Delta X_{i 1}$; and (ii) a vector of unobservable characteristics $\Delta X_{i 2}$. Lastly, $\Delta X_{i=} \Delta X_{i 1}+\Delta X_{i 2}$, so:

$$
U_{i I}-U_{i F}=\alpha\left(0.07 Y_{i}-P_{i I}\right)+\beta\left(\Delta X_{i 1}+\Delta X_{i 2}\right)+\gamma\left(\Delta X_{i 1}+\Delta X_{i 2}\right) Z_{i}+\Delta \varepsilon_{i}
$$

In the estimation, an unobservable is assumed for each option (FONASA or Isapre), so, the difference for this unobservable is normalized to 1. As the sociodemographic characteristics of the individual are the same regardless of their choice,

$$
I=U_{i I}-U_{i F}=\alpha\left(0.07 Y_{i}-P_{i I}\right)+\beta_{1} \Delta X_{i 1}+\beta_{2} \Delta X_{i 2}+\gamma_{1} \Delta X_{i 1} Z_{i}+\gamma_{2} Z_{i}+\Delta \varepsilon_{i}
$$

Unlike previous studies, this model does not use the individual risk factor as a proxy variable for the price of private insurance, but instead a vector of estimated prices according to the contributor's age, number of dependants and income level. ${ }^{8}$ Use of the price vector rather than the individual-risk proxy variable allows the new estimated price for PGS to be used as a counterfactual in the decision model, which makes it possible to simulate individuals' choices between public and private insurance following implementation of the reform. In particular, the study evaluates a single community premium. This is an average price and not the price that the average individual observes, so it biases the results; but it is a better approximation than those previously reported in the literature.

Once the effect of the reform on the relative size of the two systems and their characteristics in terms of income, age, family size and health status of individuals that move from one system to the other, this analysis will make it possible to estimate the eventual fiscal cost of the reform, to the extent that affiliates who spend more than they contribute move to FONASA.

As this research only models the demand side, it implicitly assumes a scenario where the supply is adjusted to maintain the economic rent perceived by the constant sector. This requires a significant increase in the price of PGS, which explains the fall in the demand for the Isapre service. This can then be considered an extreme scenario. If the Isapres have large economic rents, they could for example reduce the impact of the reform, by absorbing the higher costs entailed by this more solidarity-based system, generating a smaller price increase, reducing the final price to their affiliates and thus mitigating the drop in demand.

\section{Data}

The data used in this study were obtained from CASEN 2013, which provides information on individuals' housing conditions, employment status, educational level, health conditions and demographic characteristics. The survey, which questioned 66,724 households across Chile between November 2013 and January 2014, is representative nationally, by urban and rural area, for the 15 regions of the country and for a total of 324 boroughs (comunas).

\footnotetext{
8 Authors' estimation from data extracted from Duarte (2012).
} 
One of the necessary requirements for using the discrete-choice model is that the alternatives facing an individual must be mutually exclusive. For this reason, the decision model only applies to employees, manual labourers or retirees, because these individuals are subject to the mandatory health contribution, so they have to choose between contracting a plan in an Isapre or joining FONASA, paying at least $7 \%$ of their wage in both cases.

The developed model is applied to the head of the family nucleus, since it is he/she who chooses which health insurance alternative to affiliate to, according to his/her individual characteristics and those of the family nucleus, and the attributes offered by the available alternatives. The CASEN 2013 survey contains 218,490 observations, distributed among 78,938 households. The expanded sample has a population of 17,273,085 people, distributed over 6,256,912 homes.

As noted above, the sample for analysis includes only employees, labourers and retirees with a non-zero taxable income and who are affiliated to the Isapre system or FONASA groups B, C and D. Table 1 reports the distribution of total health system affiliates in 2013.

Table 1

Chile: distribution of affiliates by income quintile and type of health insurance, 2013 (Percentages)

\begin{tabular}{lcccccc}
\hline & Quintile I & Quintile II & Quintile III & Quintile IV & Quintile V & Total \\
\hline FONASA & 11.0 & 18.4 & 17.6 & 15.6 & 7.0 & 69.6 \\
\hline Isapres & 0.7 & 0.5 & 1.6 & 4.6 & 15.2 & 22.6 \\
\hline Other & 1.2 & 1.2 & 1.2 & 2.1 & 2.0 & 7.7 \\
\hline Total & 12.9 & 20.1 & 20.4 & 22.4 & 24.2 & 100.0 \\
\hline
\end{tabular}

Source: Prepared by the authors, on the basis of data from the National Socioeconomic Survey 2013.

Table 2 shows the 2013 distribution of total affiliates between the public and private systems in the final sample. Table 3 displays a number of demographic characteristics of the final sample.

Table 2

Chile: distribution of affiliates by income quintile and type of health insurance after purging the sample, 2013

(Percentages)

\begin{tabular}{lcccccc}
\hline & Quintile I & Quintile II & Quintile III & Quintile IV & Quintile V & Total \\
\hline FONASA & 9 & 21 & 20 & 17 & 7 & 74 \\
\hline Isapres & 1 & 1 & 2 & 5 & 17 & 26 \\
\hline Total & 9.3 & 21.8 & 21.9 & 22.7 & 24.2 & 100.0 \\
\hline
\end{tabular}

Source: Prepared by the authors, on the basis of data from the National Socioeconomic Survey 2013.

A major disadvantage in using surveys is that they contain data declared by the affiliates themselves, which may be subject to serious inaccuracies. In this case, for example, information on individual income corresponds to the value declared as net rather than gross income. To be used in the model, this value is transformed into taxable income, adjusting the corresponding values of income tax and health and pension fund contributions. Moreover CASEN 2013 does not contain effective information on the number of dependants per affiliate, which is why members of the family nucleus under 18 , or over 18 but under 25 if attending an educational establishment are considered as dependants. It is also not possible to distinguish how the corresponding expenses are distributed in families in which both spouses work and contribute to the health system. For this reason, it is assumed that the head of the family nucleus makes the decision and bears all the expenses. 
The public insurance premium, $7 \%$ of the wage, was estimated using a variable that represents the wage of the head of the family nucleus. If the spouse is an employee, labourer or retiree, his/her wage is attributed to this variable, which defines a "single contributor", who is assumed to bear all family expenses. This simplification reduces the problem of the lack of information on the distribution of expenses between the spouses. Nonetheless, it assumes that spouses who work and pay contributions choose the same health system.

For the private insurance premium, as noted above, an average estimate will be used according to the affiliate's age, number of dependants and income level, using data from the Superintendency of Health Insurance Institutions.

The other variables used in this study represent the individual characteristics of the survey respondents, frequently used in the studies reviewed for the Chilean case. These variables are used on a standalone basis in the model, and also to interact with the variables that contain the attributes related to the quality and service of public and private health insurance providers. These include: age, an indicator of gender, an indicator of whether the head of the family has a spouse, the number of dependants and two indicators of geographical location (one corresponding to Santiago and the other representing whether the individual lives in a small city). Tables 3 and 4 show selected statistics on these variables.

Table 3

Chile: descriptive statistics, by quintile and system, 2013

(Percentages, years of age, Chilean pesos and number)

\begin{tabular}{llrrrrr}
\hline \multirow{2}{*}{ Affiliates } & System & Quintile I & Quintile II & Quintile III & Quintile IV & \multicolumn{2}{c}{ Quintile V } \\
\hline \multirow{2}{*}{ Female affiliates } & FONASA & 94.3 & 97.3 & 91.0 & 76.5 & 28.7 \\
\cline { 2 - 7 } & Isapres & 5.7 & 2.7 & 9.0 & 23.5 & 71.4 \\
\hline \multirow{2}{*}{ Male affiliates } & FONASA & 97.3 & 97.7 & 95.6 & 79.7 & 33.6 \\
\cline { 2 - 7 } Isapres & 2.7 & 2.3 & 4.4 & 20.3 & 66.4 \\
\hline \multirow{2}{*}{ Average age (years) } & FONASA & 92.3 & 97.0 & 89.5 & 75.4 & 27.3 \\
\cline { 2 - 7 } Average taxable income & Isapres & 7.7 & 3.0 & 10.5 & 24.6 & 72.7 \\
\cline { 2 - 7 } (Chilean pesos) & FONASA & 51.3 & 49.1 & 46.7 & 46.7 & 47.1 \\
\hline \multirow{2}{*}{ Average risk } & Isapres & 51.4 & 42.3 & 41.9 & 44.4 & 43.6 \\
\hline \multirow{2}{*}{ Dependants } & Isapres & 198771 & 271453 & 364389 & 549420 & 1181443 \\
\hline
\end{tabular}

Source: Prepared by the authors, on the basis of data from the National Socioeconomic Survey 2013.

Table 4

Chile: descriptive statistics of independent sociodemographic variables, 2013

\begin{tabular}{lcc}
\hline Variable & Mean & Standard deviation \\
\hline Age & 43.25 & 12.36 \\
\hline Education & 5.88 & 3.25 \\
\hline Spouse & 0.25 & 0.43 \\
\hline Santiago or Metropolitan Region & 0.51 & 0.50 \\
\hline Small cities & 0.41 & 0.49 \\
\hline Health status & 5.75 & 1.14 \\
\hline Risk aversion & 0.16 & 0.37 \\
\hline Pre-existing conditions & 0.23 & 0.42 \\
\hline Days of hospitalization & 0.01 & 0.11 \\
\hline Risk & 3.08 & 1.30 \\
\hline Number of people & 2.36 & 1.16 \\
\hline
\end{tabular}

Source: Prepared by the authors, on the basis of data from the National Socioeconomic Survey 2013. 
Health status variables are also used, including: two indicators of individuals' (self-reported) health status. The first takes the value 1 if the individual self-evaluates with grades 1 or 2 , ("very bad" or "bad"). The second indicator takes the value 1 if the respondent self-evaluates 3 or 4 ("less than reasonable" or "reasonable"). The remaining scores of 5, 6 and 7 correspond to "more than reasonable", "good" and "very good", respectively. These variables attempt to capture trends in adverse selection and moral hazard after the implementation of the reform. A variable is constructed that captures the sum of the risk factors among the dependants and the head of the family nucleus. This is based on a table of risk factors updated to 2009, calculated from a weighted average of the tables of Isapres functioning in 2005 and the proportion of beneficiaries of each Isapre operating in 2009.

Lastly, the model incorporates quality and service variables to represent another dimension of the attributes of health insurance. Firstly, using data from the Department of Health Statistics and Information (DEIS) of the Ministry of Health, ${ }^{9}$ the number of health facilities available per 100,000 inhabitants in each region for each system is constructed, as shown in table 5 . Secondly, a variable is constructed to represent affiliates' average expenses in the two systems, by region. ${ }^{10}$

Table 5

Chile: number of health facilities, by region, 2013 (Per 100,000 inhabitants)

\begin{tabular}{lcc}
\hline Region & Isapres & FONASA \\
\hline$I$ & 0.65 & 0.33 \\
\hline$\|$ & 1.58 & 0.35 \\
\hline$I I$ & 1.08 & 0.36 \\
\hline$I V$ & 0.28 & 0.42 \\
\hline$V$ & 0.63 & 0.46 \\
\hline$V I$ & 0.34 & 0.23 \\
\hline$V I I$ & 0.30 & 0.30 \\
\hline$V I I$ & 0.59 & 0.40 \\
\hline$X$ & 0.31 & 0.31 \\
\hline$X I$ & 0.24 & 0.36 \\
\hline$X I I$ & 0.96 & 0.96 \\
\hline RM & 1.27 & 0.63 \\
\hline$X I V$ & 1.03 & 0.34 \\
\hline$X V$ & 0.53 & 0.26 \\
\hline$S O u$ & 3.23 & 0.54
\end{tabular}

Source: Prepared by the authors, on the basis of data from the Department of Health Statistics and Information of the Ministry of Health.

Table 6 shows the differences in the averages of the quality and service variables, by income quintile.

9 The most recent DEIS database of hospital discharges is used for 2011. To construct the index, only hospitals classified as more complex establishments are selected. Rural health posts, and urban, family, family-community or rural health centres are not considered; nor are vaccination centres, facilities of medium or lower complexity, field hospitals or military campaign hospitals, primary emergency care services (SAPU); mobile dental clinics, sanitary bureaus, clinics under contract, general rural consulting rooms, closed care centres; health referral centres, therapeutic diagnostic centres and delegated hospitals. In the case of private establishments, only hospitals and clinics are included.

10 The average is calculated including emergency and specialty medical consultations, x-rays or ultrasound procedures and preventive check-ups. The average does not include expenses in respect of hospitalization or surgery. The averages are based on data from the Social Protection Survey (EPS) of 2009; it was decided not to work with the latest available EPS (2012), since the Undersecretariat of Social Security considers it unreliable. 
Table 6

Chile: quality variables, by income quintile, 2009

(Chilean pesos)

\begin{tabular}{lcccrr}
\hline & Quintile I & Quintile II & Quintile III & Quintile IV & Quintile V \\
\hline Average co-payment difference & 20178 & 17502 & 14862 & 12809 & 9254 \\
\hline Average difference in hospitals per inhabitant & 0.32 & 0.43 & 0.53 & 0.56 & 0.64 \\
\hline
\end{tabular}

Source: Prepared by the authors, on the basis of data from the 2009 Social Protection Survey.

Lastly, other variables are used for the purpose of replicating previous results, such as: the logarithm of the income of the head of the family nucleus; a price variable (risk factor) in two versions - one with the same data used by Sapelli and Torche (2001) and another updated to 2009- calculated from a weighted-average of the tables of Isapres open in 2005 and the proportion of beneficiaries of each Isapre open in 2009; and the number of members of the family nucleus who have been hospitalized for more than eight days in the three months prior to the survey.

\section{Results}

The demand for private health insurance is a function of the difference in prices between public and private insurance: the more negative this difference, the less likely it is that the individual will join an Isapre. The equation also includes insurance quality and service attributes, described in the vector of observable attributes: the better the quality and service of Isapre plans compared to FONASA, the more likely it is that the individual will choose an Isapre. Given the normalization of the vector of unobservable attributes, the individual's sociodemographic characteristics in themselves represent an effect in terms of preference for a health plan. Similarly, individual characteristics, such as age, income, gender, sector of residence and others, influence how people perceive the specific attributes of each plan. For this reason, the model includes a series of interactions between individual sociodemographic variables and health insurance quality and service variables, to more effectively characterize the population's heterogeneous preferences. The main purpose of the analysis is to study the individual's sensitivity to changes in the health insurance premium, while controlling for sociodemographic and quality variables. This approach makes it possible to analyse how the reform may affect adverse selection, which could affect the public insurance because the public system does not impose restrictions on accepting affiliates with any type of risk or expected cost to the system.

\section{Comparison of the results with those reported in the literature}

The variable of interest is a binary variable that takes the value 1 if the individual chooses the Isapre system and 0 if he/she chooses FONASA. Table 7 shows the results of the regression for the model proposed by Sapelli and Torche. Regression A replicates the model using the risk factor table used in the original model; B uses the updated risk factor table and, lastly, $\mathrm{C}$ uses the price vector constructed on the basis of the real prices paid by individuals.

The results reported in the table show that price sensitivity has ceased to be significant for 2013 (regression A), while income sensitivity has remained. The use of the risk factor as a proxy for the private premium (regression B) is not significant, unlike the price created from real premiums (regression C). This implies that the risk factor would not be the most efficient proxy variable for the average price, because it does not incorporate the effect of the basic premium, which is different for each plan. 
Table 7

Chile: coefficients and standard deviations of the regressions

\begin{tabular}{|c|c|c|c|c|c|c|c|}
\hline \multirow{2}{*}{ Variables $^{\mathrm{a}}$} & $\begin{array}{c}\text { Sapelli and Torche } \\
\text { CASEN } 1996\end{array}$ & Regression A & CASEN2013 & Regression B & CASEN2013 & Regression C & CASEN2013 \\
\hline & Coefficients & Coefficients & $\begin{array}{l}\text { Standard } \\
\text { deviation }\end{array}$ & Coefficients & $\begin{array}{l}\text { Standard } \\
\text { deviation }\end{array}$ & Coefficients & $\begin{array}{l}\text { Standard } \\
\text { deviation }\end{array}$ \\
\hline L_ingreso & $2.10^{\star *}$ & $2.647^{* \star *}$ & 0.199 & $2.650^{* * \star}$ & 0.198 & $2.906^{\star \star \star}$ & 0.183 \\
\hline Precio & $-0.20^{\star \star}$ & -0.105 & 0.079 & -0.081 & 0.077 & $-0.0142^{\star \star}$ & 0.005 \\
\hline Cónyuge & $0.47^{\star \star}$ & $0.332^{\star \star \star}$ & 0.079 & $0.301^{* \star *}$ & 0.081 & $0.439^{\star \star \star *}$ & 0.075 \\
\hline Edad & $-0.04^{\star \star}$ & -0.004 & 0.003 & -0.002 & 0.003 & $-0.0101^{* *}$ & 0.003 \\
\hline Días_Hosp & -0.49 & -0.002 & 0.102 & 0.002 & 0.094 & -0.044 & 0.095 \\
\hline Santiago_RM & $5.11^{\star \star}$ & 3.824 & 2.905 & 4.140 & 2.898 & $5.875^{\star}$ & 2.750 \\
\hline Ciud_Pequeñas & $3.32^{\star *}$ & 4.724 & 2.912 & 4.961 & 2.908 & $7.048^{\star}$ & 2.755 \\
\hline Lin_Stgo & $-0.29^{*}$ & -0.168 & 0.218 & -0.174 & 0.217 & -0.348 & 0.208 \\
\hline Lin_Pequeñas & -0.18 & -0.290 & 0.218 & -0.301 & 0.218 & $-0.481^{*}$ & 0.209 \\
\hline Pre_Stgo & -0.05 & -0.127 & 0.092 & -0.170 & 0.087 & 0.000 & 0.000 \\
\hline Pre_Pequeñas & -0.03 & -0.054 & 0.088 & -0.065 & 0.084 & 0.000 & 0.000 \\
\hline Constant & $-24.84^{\star \star \star}$ & $-36.91^{\star \star \star}$ & 2.644 & $-37.01^{\star \star \star}$ & 2.63 & $-40.21^{\star \star \star}$ & 2.407 \\
\hline Pseudo- $R^{2}$ & 0.26 & 0.377 & & 0.378 & & 0.373 & \\
\hline
\end{tabular}

Source: Prepared by the authors.

Note: $\quad{ }^{* \star *}$ Significant at $1 \%$; ${ }^{*}$ significant at $5 \%$; * significant at $10 \%$.

a These variables are as defined in Sapelli and Torche (1998): L_ingreso (logarithm of income); Precio (price - the constructed index); Cónyuge (spouse dummy variable); Edad (age); Días_Hosp (number of family members who have been hospitalized for more than eight days in the last three months); Santiago_RM (dummy variable identifying Santiago (Chile)); Ciud__Pequeñas (dummy variable identifying small cities); Lin_Stgo and Lin_Pequeñas (interactions between the dummy variables of cities and the logarithm of income); Pre_Stgo and Pre_Pequeñas (interactions between city dummy variables and price).

\section{Results of the proposed model}

Table 8 shows the regression results for the proposed model. The variable Dif_Precio represents the difference between the public and private premiums. As expected, the more negative the price difference between public insurance and private insurance, the smaller the chance of affiliation to the Isapre system. The other variables related to health insurance attributes of were constructed as their value in the case of private insurance minus their value in public insurance.

A greater difference in co-payments between Isapres and FONASA (the Dif_Copago_sis variable) implies a higher probability of affiliating to FONASA. On the other hand, a larger difference between the number of health-care facilities in the individual's region increases the likelihood of affiliation to the Isapre system.

The positive sign found for the age variable ( $E$ dad) indicates an increase in the risk profile of Isapre affiliates. One possible reason for this effect is the introduction of the additional coverage for catastrophic illnesses (CAEC) in 2006, which may have affected those with a higher health-risk profile, making private health insurance more attractive to them. Even so, the health status variable, Estado_Salud, which captures information on the individual's health risk that is not available to insurers, indicates a preference for public insurance if there is evidence of a worse health status.

On the other hand, the existence of a working spouse who pays into a health system increases the likelihood of affiliation to Isapres, due to the interaction between the Dif_Copago_sis and Cónyuge (spouse) variables and despite the larger co-payments in the private system. This is because a working spouse increases family income, which explains a greater preference for the Isapre system.

On average, the Santiago_RM and Ciud_Pequeñas variables show that people living in metropolitan Santiago or small cities have a stronger preference for Isapres. Moreover, as expected, an increase in income increases the likelihood of affiliation to the private system. 
Table 8

Chile: coefficients and standard deviations of the regression of the proposed model

\begin{tabular}{|c|c|c|}
\hline & Coefficients & Standard deviation \\
\hline Dif_Precio & 0.076 & 0.047 \\
\hline Dif_Copago_Sis & -0.647 & 0.740 \\
\hline Dif_Hosp_Hab & 0.763 & 0.505 \\
\hline Ysueldo & $0.000^{\star \star \star}$ & 2.61E-07 \\
\hline Edad & 0.002 & 0.006 \\
\hline Sexo & -0.185 & 0.119 \\
\hline Cónyuge & 0.323 & 0.177 \\
\hline Estado_Salud1 & 0.083 & 0.616 \\
\hline Estado_Salud2 & -0.511 & 0.272 \\
\hline Santiago_RM & $1.495^{\star \star \star}$ & 0.297 \\
\hline Ciud_Pequeñas & $0.797^{\star \star}$ & 0.265 \\
\hline Num_Pers & 0.003 & 0.0818 \\
\hline Dif_Cop x Ysueldo & 0.000 & $4.85 \mathrm{E}-07$ \\
\hline Dif_Cop x Edad & -0.000 & 0.011 \\
\hline Dif_Cop x Sexo & 0.152 & 0.234 \\
\hline Dif_Cop x Cónyuge & 0.325 & 0.221 \\
\hline Dif_Cop x Salud1 & 0.739 & 0.613 \\
\hline Dif_Cop x Salud2 & 0.555 & 0.313 \\
\hline Dif_Cop x Numpers & -0.069 & 0.144 \\
\hline DifHosp x Ysueldo & 0.000 & $5.08 \mathrm{E}-07$ \\
\hline DifHosp x Edad & $-0.012^{*}$ & 0.005 \\
\hline DifHosp x Sexo & -0.203 & 0.145 \\
\hline DifHosp x Cónyuge & $-0.593^{\star \star \star}$ & 0.154 \\
\hline DifHosp x Salud1 & -0.312 & 0.386 \\
\hline DifHosp x Salud2 & 0.109 & 0.163 \\
\hline DifHosp x Santiago_RM & $0.889^{\star}$ & 0.383 \\
\hline DifHosp x Ciud_Peq & 0.357 & 0.246 \\
\hline DifHosp x Numpers & -0.103 & 0.0587 \\
\hline DifPrecio x Cónyuge & -0.034 & 0.0334 \\
\hline DifPrecio x Salud1 & 0.118 & 0.104 \\
\hline DifPrecio x Salud2 & -0.025 & 0.0403 \\
\hline DifPrecio x Santiago_RM & 0.043 & 0.0528 \\
\hline DifPrecio x Ciud_Peq & -0.026 & 0.047 \\
\hline Constant & $-3.836^{\star \star \star}$ & 0.394 \\
\hline
\end{tabular}

Source: Prepared by the authors.

Note: ${ }^{* \star \star}$ significant at $1 \%$; ${ }^{*}$ significant at $5 \%$; ${ }^{*}$ significant at $10 \%$.

\section{Effects of the implementation of the Guaranteed Health Plan with a single community premium}

Using the model described in the foregoing sections, the transfer of affiliates between the Isapre and FONASA systems is estimated after the implementation of PGS with a single community premium. For the purposes of the simulation, the data provided on the PGS coverage level by the Health Reform Commission were corrected. An average coverage level of 75\% was assumed, at 2013 prices. This generates a flat rate of Ch\$26,989, above the range estimated by CRS, which considered lower coverage (50\% in ambulatory FONASA free-choice and 60\% for hospitalization in the José Joaquín Aguirre Clinical Hospital of the University of Chile). This increase in coverage was considered to approach the proposal made in the Senate Health Committee, ${ }^{11}$ which, at current prices, implies a cost estimated

\footnotetext{
${ }^{11}$ The Ministry's proposal considers 80\% hospitalization coverage (J. J. Aguirre hospital fee) and 60\% ambulatory coverage, thereby raising the coverage defined in the Health Reform Council study.
} 
by the Ministry of Health of a flat rate Ch\$28,432 to pesos per person at 2013 prices. ${ }^{12}$ The value of Ch\$26,989 per beneficiary was obtained by imposing the $75 \%$ coverage and calculating the premium generated by the same total profit margin of the Isapre system as existed pre-reform. This value could overestimate the community premium if the total profit margin falls as a result of the increased competition that could be generated by eliminating the pre-existing conditions and waiting periods within the Isapre system. Lastly, it should be noted that the value includes a work disability subsidy (SIL) of $1.5 \%$ of the affiliate's average wage.

The results obtained and displayed in table 9 indicate that $12.39 \%$ of the Isapre system's total portfolio, or roughly 1 million people, transferred to FONASA. In all the quintiles the net effect is a transfer from Isapres to FONASA, but it is the lower-income groups that move on a massive scale.

Table 9

Chile: changes in the Isapres portfolio, by quintile

(Percentages)

\begin{tabular}{lcc}
\hline Income quintile & Variation in Isapre portfolio & Group-specific variation \\
\hline I & -0.83 & -71.64 \\
\hline II & -2.41 & -53.10 \\
\hline II & -3.46 & -36.45 \\
\hline V & -3.94 & -18.27 \\
\hline Total & -1.76 & -2.78 \\
\hline
\end{tabular}

Source: Prepared by the authors, on the basis of regression results and simulated scenario with the Guaranteed Health Plan.

A comparison of the proportion of affiliates that changed by income quintile, relative to each group's initial participation in the Isapres, shows that the effect of the reform is to accentuate adverse selection against FONASA. Only $1.76 \%$ of the families that change belong to the fifth quintile, yet that group represents $63.74 \%$ of Isapre affiliates (see figure 1 ). ${ }^{13}$

Figure 1

Chile: participation in the Isapres, by income quintile, 2013

(Percentages)

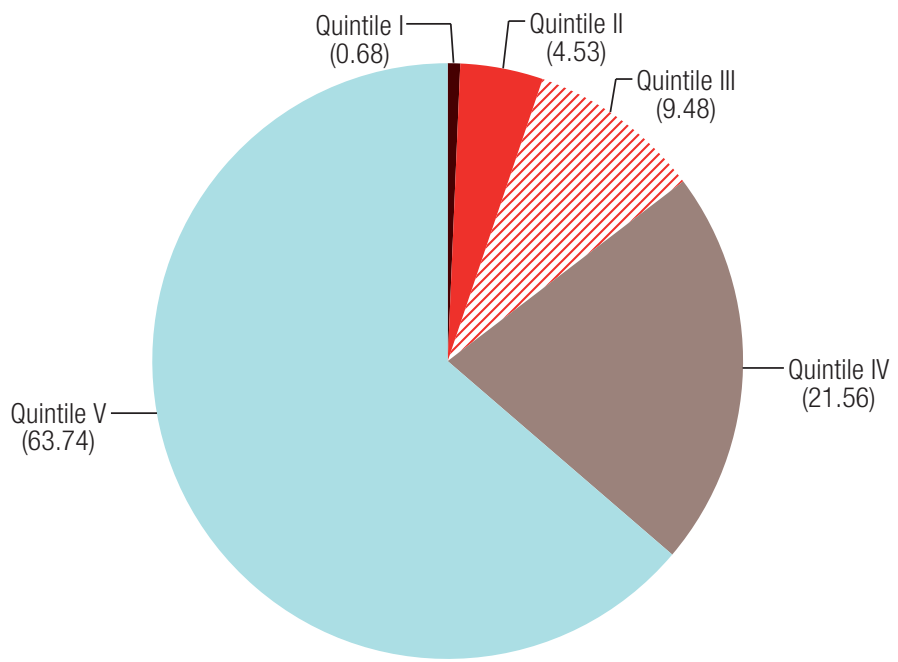

Source: Prepared by the authors, on the basis of data from the National Socioeconomic Survey 2013.

\footnotetext{
12 Report of the Minister of Health to the Senate Health Committee, June 2013.

13 The lowest-income families are over-represented among those who migrate to FONASA, relative to the average Isapre population.
} 
A higher proportion of large families change than single individuals or small families. As shown in table $10,20.26 \%$ of families with four or more members switch to FONASA; this group represents $15 \%$ of the total system (see figure 2).

Table 10

Chile: changes in Isapre portfolio, by family group

(Percentages)

\begin{tabular}{lcc}
\hline Family nucleus & Variation in Isapre portfolio & Group-specific variation \\
\hline 1 person & -1.96 & -5.69 \\
\hline 2 persons & -3.44 & -12.34 \\
\hline 3 persons & -3.87 & -17.42 \\
\hline 4 persons or more & -3.12 & -20.26 \\
\hline Total & -12.39 & -12.39 \\
\hline
\end{tabular}

Source: Prepared by the authors, on the basis of regression results and simulated scenario with the Guaranteed Health Plan.

\section{Figure 2}

Chile: participation in the Isapres, by family group, 2013 (Percentages)

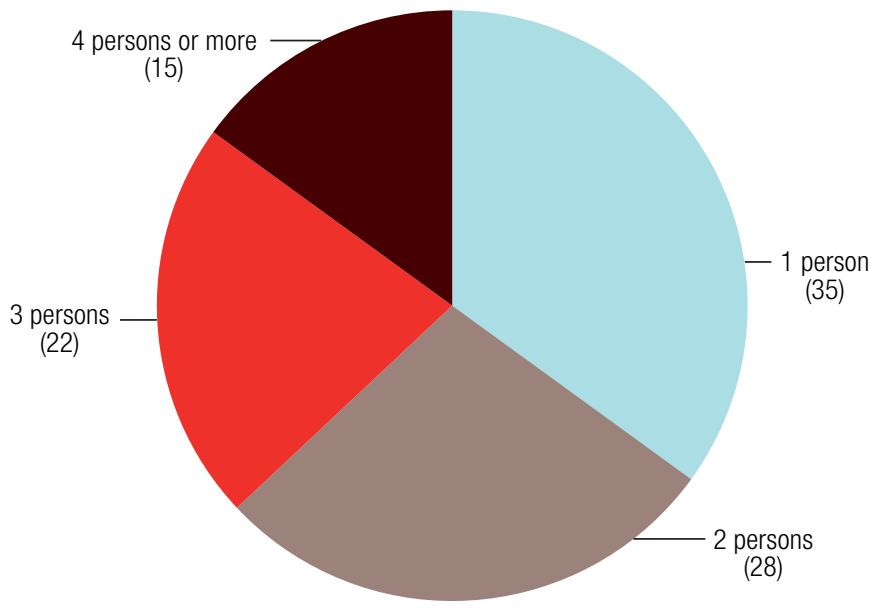

Source: Prepared by the authors, on the basis of data from the National Socioeconomic Survey 2013.

This also represents an adverse selection effect that generates an increase in the FONASA deficit, since FONASA families pay a contribution that is proportional to their income (7\%) but the expense depends on the number of dependants.

Table 11 shows that the health status of persons who migrate to FONASA is not a significant factor generating adverse selection (see also figure 3).

\section{Table 11}

Chile: changes in the Isapre portfolio, by health status (Percentages)

\begin{tabular}{lcc}
\hline Health status & Variation in Isapre portfolio & Group-specific variation \\
\hline Good & -9.69 & -10.52 \\
\hline Reasonable & -3.09 & -46.83 \\
\hline Bad & 0.40 & 33.04 \\
\hline Total & -12.39 & -12.39 \\
\hline
\end{tabular}

Source: Prepared by the authors, on the basis of regression results and simulated scenario with the Guaranteed Health Plan. 
Figure 3

Chile: participation in Isapres, by health status, 2013

(Percentages)

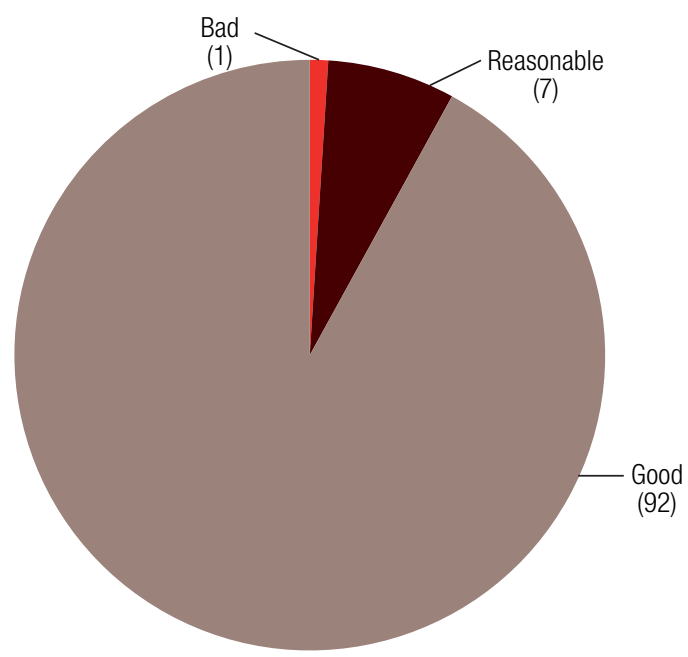

Source: Prepared by the authors, on the basis of data from the National Socioeconomic Survey 2013.

Lastly, in order to simulate the cost to FONASA of the 400,000 beneficiaries transferring from Isapres, we consider the data available up to 2011 on costs for FONASA group D as an estimate of the cost of care, adjusted by the health CPI up to 2013 and considering a cost for FONASA of Ch\$26,190. ${ }^{14}$

As the FONASA premium is $7 \%$ of income, from which the Subsidy for Work Disability due to Illness must be financed (1.5\% of income), the income of those that switch system averages Ch\$251,003 and the average number of family members is 2.9 , so the average contribution per beneficiary is Ch\$5,522 per month. The monthly FONASA deficit for each person who changes would be Ch\$20,668. Considering the price situation of 2013, the annual deficit per beneficiary transferred would be Ch\$248,015, similar to FONASA's total expenditure per average beneficiary. In conclusion, the reform implies a $12 \%$ increase in FONASA expenditure to serve beneficiaries who move to the public system.

\section{Conclusions}

This study developed a discrete-choice model, using data from the CASEN 2013 survey, to model how people in Chile choose their health insurance system. Unlike previous studies, the model does not use the individual risk factor as a proxy for the price of private insurance, but uses a vector of estimated prices according to age, number of dependants and the affiliate's income level. The model also explicitly considers the influence of system quality of when selecting health insurance, which, as shown in the analysis, improves the model's explanatory capacity.

The model is used to simulate how the affiliates' choice would change when introducing a guaranteed health plan with a flat-rate premium, in other words to simulate changes in the demand for health plans, so that the results represent a partial analysis of the effect of PGS. This does not consider the possible supply-side reaction in terms of adding complementary or supplementary plans to PGS. Any such new plans would change the "total premium" and the "total coverage" that individuals would face, which would thus change the demand for health plans. For example, if an individual has strong

${ }^{14}$ See Bitran, Arpón and Debrott (2013). 
preferences for coverage, but also for price, when facing two plans that are similar in those dimensions it is unclear which would be chosen. On the other hand, if the same individual is offered a plan that complements the basic plan with an acceptable premium, the individual in question would choose this plan. This partial effect on the demand side is large enough not to be considered in a more exhaustive analysis of the supply of and demand for private insurance.

The results of the study indicate that the Isapre portfolio would shrink by $12.39 \%$, which means that around 400,000 people would switch to FONASA. ${ }^{15}$ The changers would mainly consist of large families and individuals belonging to lower income quintiles. This result exacerbates the adverse selection problems already existing in the FONASA system. In other words, the introduction of PGS would have an adverse financial impact on FONASA, thereby reducing its ability to meet its obligations.

As noted above, the reform implies a $12 \%$ increase in FONASA expenditure to serve beneficiaries who move to the public system. Considering the 2013 budget, the cost to the Treasury of implementing PGS with a flat rate is estimated at around US\$200 million per year. In addition to the financial stress implied by an immediate increase in spending of this magnitude, FONASA would have to incorporate some 400,000 people who are accustomed to a different service modality, with all the difficulties that this entails. These families will probably spend more than the average of FONASA group D affiliates, since they are accustomed to the free-choice modality. Moreover, this massive change would to some extent displace the current FONASA population in the use of resources, since the latter has less training in the use of insurance policies and fewer resources.

In conclusion, it is not advisable to implement a Guaranteed Health Plan with a single community premium in a health insurance system as segmented as Chile's, since it tends to exacerbate the problem of adverse selection already present in the system, increasing segmentation and requiring a huge amount of additional State funding. Accordingly, the recommendation is to analyse a more inclusive pricing policy for PGS, addressing demand on a differentiated and comprehensive basis (between the public and private system), with premiums that differ according to factors such as the age and socioeconomic level of the affiliates and the interaction with supply.

\footnotetext{
15 The simulation is based on 2 million affiliates, who represent a large percentage of the total portfolio. This is necessary owing to the data restrictions that apply when using surveys. In particular, the database excludes self-employed affiliates, which could introduce a bias.
} 


\section{Bibliography}

Akerlof, G. A. (1970), "The market for 'lemons': quality uncertainty and the market mechanism”, The Quarterly Journal of Economics, vol. 84, No. 3.

Bitran, R., P. Arpón and D. Debrott (2013), "Opciones de reforma a la seguridad social en salud en Chile", Documento de Referencia, No. 13, Santiago, Espacio Público.

Copetta, C. (2011), "Minuta Plan Garantizado de Salud Para el Sector Isapres", Working Paper, Santiago, Superintendence of Health.

Cutler, D. M. and S. J. Reber (1998), "Paying for health insurance: the trade-off between competition and adverse selection", The Quarterly Journal of Economics, vol. 113, No. 2, Oxford, Oxford University Press.

Dawes Ibáñez, A. (2010), "Health care reform and its effect on the choice between public and private health insurance: evidence from Chile", thesis, Santiago, Institute of Economics, Catholic University of Chile.

Duarte, F. (2012), "Price elasticity of expenditure across health care services", Journal of Health Economics, vol. 31, No. 6, Amsterdam, Elsevier.

Feldman, R. and others (1989), "The demand for employment-based health insurance plans", Journal of Human Resources, vol. 24, No. 1, Wisconsin, University of Wisconsin Press.

Friedman, B. (1974), "Risk aversion and the consumer choice of health insurance option", The Review of Economics and Statistics, vol. 56, No. 2, Cambridge, Massachusetts, The MIT Press.

Missoni, E. and G. Solimano (2010), "Towards universal health coverage: the Chilean experience", World Health Report (2010) Background Paper, No. 4, World Health Organization (WHO) [online] https://pdfs.semanticscholar. org/226c/4621cd397092dfd556f7b19f02048d6f5620.pdf?_ga=2.163282104.523300194.15019662371570332244.1501185329.

Sanhueza, R. and J. R. Tagle (2002), "Choosing health insurance in a dual health care system: the Chilean case", Journal of Applied Economics, No. 001.

Sapelli, C. and A. Torche (2001), "The mandatory health insurance system in Chile: explaining the choice between public and private insurance", International Journal of Health Care Finance and Economics, vol. 1, No. 2, Springer.

(1998), "El seguro previsional de salud: determinantes de la elección entre seguro público y privado, 1990-1994", Cuadernos de Economía, vol. 35, No. 106, Santiago, Institute of Economics, Catholic University of Chile.

Sapelli, C. and B. Vial (2003), "Self-selection and moral hazard in Chilean health insurance", Journal of Health Economics, vol. 22, No. 3, Amsterdam, Elsevier.

Superintendency of Health (2012), "Estudio de opinión y satisfacción de usuarios", Santiago [online] http:// www.supersalud.gob.cl/documentacion/666/articles-7632_recurso_1.pdf.

Tokman, M., C. Marshall and C. Espinosa (2007), "Un matrimonio difícil: la convivencia entre un seguro público solidario y seguros de salud competitivos", Financiamiento del Desarrollo series, No. 199 (LC/L.2851-P), Santiago, Economic Commission for Latin America and the Caribbean (ECLAC). 